\title{
Fatigue in Inflammatory Bowel Diseases: Etiologies and Management
}

Angelica Nocerino - Andrew Nguyen - Manasi Agrawal •

Anjali Mone $\cdot$ Komal Lakhani $\cdot$ Arun Swaminath

Received: August 8, 2019 / Published online: November 23, 2019

(C) The Author(s) 2019

\section{ABSTRACT}

Fatigue is a burdensome, multidimensional, and multifactorial symptom that is associated with a wide array of chronic illnesses, specifically occurring in nearly $50 \%$ of patients with inflammatory bowel disease (IBD). Although common, given its subjective nature, physicians often under-recognize and undertreat this debilitating symptom. There are multiple etiologies that can contribute to fatigue in patients with IBD, including disease activity, anemia, medications, psychosomatic symptoms, and alterations to the gut-brain axis. The management of fatigue in IBD can be challenging, as it is often times multifaceted. In

Enhanced digital features To view enhanced digital features for this article go to https://doi.org/10.6084/ m9.figshare.10011884.

A. Nocerino - A. Nguyen - A. Mone - K. Lakhani ·

A. Swaminath $(\varangle)$

Lenox Hill Hospital, Northwell Health System, New

York, NY, USA

e-mail: aswaminath@northwell.edu

M. Agrawal

Department of Gastroenterology, Mount Sinai

Hospital, New York, NY, USA this review, we summarize the available tools for the diagnosis and measurement of fatigue, discuss etiologies, and make recommendations for their management. We identify knowledge gaps for the workup and treatment of fatigue and propose an algorithm to aid physicians in the evaluation and management of fatigue in this unique population. However, future research is needed to address several areas of knowledge deficits and improve the management of fatigue in IBD.

Keywords: Anemia; Crohn's disease; Disease activity; Fatigue; Inflammatory bowel disease; Ulcerative colitis 


\section{Key Summary Points}

Why carry out this study?

Fatigue is a debilitating, under-recognized, multifactorial symptom occurring in nearly $50 \%$ of patients with inflammatory bowel disease (IBD); yet there exist knowledge gaps and a lack of consensus on the workup and management of fatigue in this patient population

The objective of this study is to propose a systematic approach to address fatigue in patients with IBD

\section{What was learned from this study?}

Fatigue may reflect persistently active disease, complications from active disease, medication adverse effect, altered gut microbiome, sleep disturbances, or psychosomatic symptoms

This review provides an algorithmic approach for the diagnosis and management of fatigue in patients with IBD

\section{INTRODUCTION}

Fatigue implies lack of energy or exhaustion out of proportion to physical exertion, with limitation of daily activities, and which is not relieved by rest [1]. Fatigue is associated with many chronic inflammatory conditions, such as inflammatory bowel disease (IBD), rheumatoid arthritis, and multiple sclerosis, and leads to an adverse impact on quality of life (QoL). Although common, fatigue often goes underrecognized and untreated in the IBD population, detrimentally affecting patients' quality of life. Healthcare providers expressed frustration in addressing this complaint because of a perceived gap in knowledge to effectively address it [2].
Fatigue is twice as common in patients with IBD as in healthy controls [3]. It occurs in up to $50 \%$ of patients with IBD at diagnosis, and is more common in Crohn's disease (CD) (48-62\%) than it is in ulcerative colitis (UC) (42-47\%) [4]. Multiple studies have shown that fatigue is associated with disease severity $[5,6]$. One single-center cross-sectional study showed that fatigue has an inverse relationship with clinical and endoscopic remission, and that deep remission has lower rates of fatigue complaints compared to clinical remission only [7]. In another cross-sectional study of 247 patients with IBD, lack of energy was the most burdensome symptom, more so than gastrointestinal complaints, such as diarrhea [8]. Fatigue occurs in patients with IBD of all ages and both sexes, although some studies suggest a greater burden in women [9]. It is also associated with lack of education beyond primary school, part-time work schedule, and other comorbid conditions [10]. Risk factors, in addition to IBD, are underlying psychological distress, sleep disturbances, and anemia [5, 6]. As expected, fatigue is associated with a detrimental impact on QoL and functioning, irrespective of disease activity [11-13]. In a prospective study of 440 patients, decrease in work productivity, i.e., presenteeism, was seen in $62.9 \%$ of patients with IBD and $27.3 \%$ of controls $(p=0.004)$. There was also higher indirect medical costs in patients with IBD than controls $(\$ 17,766$ per year versus $\$ 9179$ per year, respectively, $p<0.03$ ) [14]. Another study corroborated this association of fatigue with presenteeism and general activity impairment in patients with IBD, rheumatoid arthritis, and multiple sclerosis after controlling for sociodemographic factors, cognitive impairment, and disability [15].

This review summarizes the current literature on fatigue in IBD, with a focus on the main etiologies of fatigue in IBD, specifically inflammation, anemia, micronutrient deficiencies, medications, gut-brain axis, and psychological disturbances (Table 1). We propose a systematic approach to the evaluation and management of fatigue in patients with IBD. This article is based on previously conducted studies and does not contain any studies with human participants or animals performed by any of the authors. 
Table 1 Etiologies of fatigue

\begin{tabular}{|c|c|}
\hline $\begin{array}{l}\text { Etiology of } \\
\text { fatigue }\end{array}$ & Mechanism of action \\
\hline Inflammation & $\begin{array}{l}\text { Inflammatory cytokines activating the } \\
\text { hypothalamic pituitary adrenal } \\
\text { (HPA) axis }\end{array}$ \\
\hline Anemia & $\begin{array}{l}\text { Chronic bleeding, iron, vitamin } \mathrm{B}_{12} \\
\text { and folate deficiency, anemia of } \\
\text { chronic disease }\end{array}$ \\
\hline $\begin{array}{c}\text { Micronutrient } \\
\text { deficiencies }\end{array}$ & $\begin{array}{l}\text { Malabsorption, diarrhea, self-imposed } \\
\text { dietary restrictions or a catabolic } \\
\text { state }\end{array}$ \\
\hline Medications & Drug adverse effect \\
\hline Gut microbiome & Dysbiosis and the gut-brain axis \\
\hline
\end{tabular}

\section{EVALUATION OF FATIGUE}

When fatigue is a pernicious symptom, a patient will generally report it to the physician. However, it can be incipient early on and remain unrecognized. Although data are lacking, an important initial step in evaluation would be to screen routinely for fatigue by simply asking the patient if they feel or have recently felt fatigued.

Several scales, developed to assess fatigue in chronic illnesses, are available for patients with IBD, as summarized in Fig. 1. The multidimensional fatigue inventory (MFI), a 20-item questionnaire, measures fatigue in five dimensions, namely general, physical, motivation, activity, and mental [16]. The MFI-20 is particularly

\begin{tabular}{|l|l|c|}
\hline Questionnaire & Validated Study & Reference Number \\
\hline $\begin{array}{l}\text { Functional Assessment of } \\
\text { Chronic Illness Therapy- } \\
\text { Fatigue (FACIT-F) }\end{array}$ & $\begin{array}{l}\text { Tinsley et al. Aliment } \\
\text { Pharmacol Ther. 2011 }\end{array}$ & 18 \\
\hline Fatigue Questionnaire (FQ) & $\begin{array}{l}\text { Chalder et al. J Psychosom } \\
\text { Res. 1993 }\end{array}$ & 19 \\
\hline $\begin{array}{l}\text { Inflammatory bowel disease } \\
\text { fatigue (IBD-F) }\end{array}$ & $\begin{array}{l}\text { Czuber-Dochan et al. J } \\
\text { Crohns Colitis. 2014 }\end{array}$ & 2 \\
\hline $\begin{array}{l}\text { Multidimensional } \\
\text { Assessment Fatigue (MAF) }\end{array}$ & Belza et al. Nurs Res. 1993 & 17 \\
\hline $\begin{array}{l}\text { Multidimensional Fatigue } \\
\text { Inventory (MFI) }\end{array}$ & $\begin{array}{l}\text { Smets et al. J Psychosom } \\
\text { Res. 1995 }\end{array}$ & 16 \\
\hline
\end{tabular}

Fig. 1 Validated questionnaires for assessing fatigue in IBD useful because it can be used to assess responsiveness to change after therapeutic interventions. This scale, although frequently used to measure fatigue in IBD, has not been validated in IBD [2]. Similarly, the Multidimensional Assessment Fatigue (MAF) scale, developed to study patients with rheumatoid arthritis, has 16 items to measure fatigue in four dimensions, namely severity, distress, degree of interference with activities of daily living, and timing of fatigue [17]. The Functional Assessment of Chronic Illness Therapy-Fatigue (FACIT-F) is a 13-question sub-scale of the Functional Assessment of Chronic Illness Therapy (FACIT) Measurement System that focuses on general fatigue, but does not take into account physical, mental, and activity as does the MFI. The FACIT-F, however, is validated to measure fatigue in chronic illnesses including IBD, with good internal consistency, reproducibility, and sensitivity [18]. In the Fatigue Questionnaire (FQ), patients rate themselves between 0 and 3; 0 and 3 indicating better than usual and much worse than usual, respectively, on each of the 11 items pertaining to physical and mental fatigue [19]. The IBD-fatigue (IBD-F) patient selfassessment scale assesses the frequency and severity of fatigue as well as patient experience. This scale has good reliability [2] as well as correlation with the MFI and MAF scales [20]. There is a lack of consensus on which scale is best to use to measure fatigue in the IBD population [21]. Of the mentioned scales, IBD-F is the only scale specific to patients with IBD. Studies have shown that IBD-F correlates to the MFI and MAF instruments. Patients with IBD prefer to use the IBD-F scale [2]. The lack of uniform scales in fatigue in IBD research limits our ability to make comparisons and generalizations.

Additionally, questions about fatigue exist among measured domains evaluated by QoL assessment tools, such as the IBD questionnaire (IBDQ) [22] and the Medical Outcomes Study 36-item Short Form Health Survey (SF-36) [23]. These patient-reported outcome (PRO) instruments were part of the FDA guidance to industry regarding recommended outcome measurements in clinical trials of IBD since 2016 [24]. Similarly, the EuroQol-5D (EQ-5D) is 
a 5-item tool to determine QoL and is validated for use in IBD [25]. However, questions about fatigue make up only 1 of 32 questions in the IBDQ, and 4 of 36 questions in the SF-36 [23]. Because studies report overall improvement in scores or list results of domains (i.e., vitality) rather than fatigue specifically, it is difficult to arrive at conclusions regarding resolution of fatigue symptoms based on published data. These tools are used primarily in clinical research studies for QoL assessment and are not common in routine clinical practice.

\section{FATIGUE IN IBD: ETIOLOGIES AND MANAGEMENT}

\section{Pro-Inflammatory State}

Fatigue is well known to occur in chronic inflammatory diseases, such as multiple sclerosis (MS) and systemic lupus erythematosus (SLE). Similarly, it occurs in patients with cancer $[26,27]$. Fatigue is hypothesized to be mediated by inflammatory cytokines [28] and an activated Th1-immune system [29], primarily through the brain-gut axis. The brain-gut axis is the bidirectional pathway between the central and enteric nervous system, mediated by the HPA axis. Pro-inflammatory cytokines, in response to environmental or clinical stress, activate the HPA axis through secretions of corticotropin-releasing factor (CRF) from the hypothalamus. CRF then stimulates the adrenocorticotropic hormone (ACTH) from the pituitary gland, which then stimulates the release of cortisol, a stress hormone, from the adrenal gland [30]. Cortisol has systemic effects and can affect the brain, resulting in fatigue [30].

Multiple studies have shown that fatigue is associated with clinically active IBD. In a singlecenter cross-sectional study, it was discovered that $48.7 \%$ of the 187 patients with IBD suffered from fatigue. After adjustment for age and sex, fatigue was inversely associated with clinical and endoscopic but not histological remission [7]. In a larger study of the Inflammatory Bowel Disease in South-Eastern Norway (IBSEN) cohort, of the 440 patients with IBD who had disease for at least 20 years and completed the FQ, those with clinically active disease had higher fatigue scores than those with inactive disease (UC 17.1 versus $12.4, p<0.001$, and CD 17.5 versus $13.3, p<0.001$ ) [6]. In a study of patients with IBD in clinical remission, the number of memory T cells and neutrophils was significantly higher $(p=0.005$ and 0.033 , respectively), while that of monocytes was lower $(p=0.011)$ in those with fatigue $(n=55)$ compared with those without fatigue $(n=29)$, as measured by the CIS-fatigue scale. Additionally, the levels of inflammatory cytokines such as tumour necrosis factor alpha (TNF $\alpha)$, interferon- $\gamma$ (IFN $\gamma$ ), interleukin-12 (IL-12), and IL-10 were significantly higher and IL-6 lower, suggesting differences in immunological activity between the two groups [29]. Furthermore, longitudinal data over 2 years from the Manitoba IBD cohort $(n=312)$ revealed that fatigue was strongly associated with inflammation [5]. In a study of 67 children with IBD, those in the lowest insulin-like growth factor I (IGF-1) $z$ score quartile had significantly greater fatigue $(p=0.02)$, as well as higher levels of IL-10, IL17A, IL-6, and IFN $\gamma$ [31] implicating inflammatory pathways in fatigue pathogenesis. However, these studies did not determine endoscopic or biochemical remission, making it difficult to determine underlying IBD-related inflammatory burden accurately. One study $(n=288)$, in which fatigue was assessed during active disease and during deep remission, those in deep remission had no significant difference in immune markers, i.e., calprotectin, C-reactive protein (CRP), IL-17A, IL-6, IL-1 $\beta$, IL-10, IL8, TNF $\alpha$, IL-13, IFN, IL-4, and IL-12, between those with fatigue and those without fatigue [9]. Thus, in quiescent disease, inflammation may not have a significant role in the pathogenesis of fatigue. However, active IBD with elevated cytokines, such as TNF $\alpha$ and IFN $\gamma$, as well as elevated fecal calprotectin, correlates with the severity of fatigue $[5,6,9,29,32-34]$.

Inflammation is associated with a greater catabolic state and increase in resting energy expenditure, which could contribute to fatigue. In a study of 75 adult patients with CD, those with active disease had higher resting energy expenditure (REE) than those in remission 
$(28.8 \pm 5.4$ vs $25.9 \pm 4.3 \mathrm{kcal} / \mathrm{kg}, \quad p<0.001)$ [35]. Furthermore, pro-inflammatory cytokines can lead to anorexia and a decrease in caloric intake [36], dysregulation of the HPA axis [37], and promote anxiety and depressive symptoms through the gut-brain axis in susceptible persons [38], which could be perceived as fatigue.

While most studies note an association of inflammation and fatigue, there is heterogeneity among published studies. In a study by Villoria et al., among 202 patients with IBD in clinical remission, there was no correlation between levels of CRP, IL-5, IL-8, and IL-12 and fatigue scores, although fatigue was prevalent in $54 \%$ of the cohort. However, in this study, endoscopic inflammation and calprotectin were not provided. The mean CRP in all three groups (none, mild, and severe fatigue) was normal and with a wide standard deviation [39]. A second prospective study of 544 patients with IBD found that fatigue was associated with anxiety, depression, and sleep disorders, but not associated with disease activity. This study, however, defined active disease in CD as a Harvey-Bradshaw index score greater than 4 points. This scoring system is based on factors including abdominal pain, abdominal mass, and complications such as arthralgia. It does not take into account objective measures of active disease, such as CRP, fecal calprotectin, endoscopic markers, of inflammation [40].

\section{Control of Inflammation}

IBD therapy and control of inflammation is consistently associated with improvement in fatigue. In post hoc analyses of various randomized trials, treatment of $\mathrm{CD}$ with infliximab, adalimumab, certolizumab, or ustekimumab over placebo is associated with improvement in fatigue, as measured by the IBDQ, SF-36, EQ-5D, and FACIT [41-44] and similarly in patients with UC, upon treatment with infliximab, adalimumab, golimumab, vedolizumab, or tofacitinib [45-49]. Improvement in fatigue has also been seen in patients with UC who were treated with non-biologic therapies, such as immunomodulators and 5-aminosalicylates (ASA) [50]. Mucosal healing is associated with improvement in fatigue [51]. Therefore, patients with ongoing fatigue symptoms in clinical remission, but not endoscopic remission, may also benefit from therapy titrated to this target.

Recently, Cannabis sativa use amongst patients with IBD has also become more prevalent with statewide legalization or decriminalization [52]. There are at least 70 known cannabinoids, which are the active ingredients of the plant, and act upon the endocannabinoid system (ECS) [53]. The ECS has a role throughout the gastrointestinal tract, regulating food intake, nausea and emesis, gastric secretion, motility, intestinal inflammation, and cell proliferation [54]. Cannabis has improved IBD-related symptoms, such as abdominal pain, diarrhea, and anorexia [55, 56]. One study assessing cannabidiol in the symptomatic treatment of UC found that fatigue was a common side effect [57]. No studies have evaluated the effect of cannabis or cannabis derivatives on fatigue among patients with IBD.

\section{Anemia}

Anemia occurs in up to $20 \%$ of ambulatory patients and up to $68 \%$ of hospitalized patients with IBD [34, 58], and is an important cause of fatigue. Iron deficiency anemia (IDA) is the most common anemia in IBD and can be due to chronic gastrointestinal bleeding and decreased nutritional intake [59]. Ongoing inflammation, mucosal ulcers, and mucosally fragile pseudopolyps can lead to IDA. Iron deficiency, without overt anemia, was not associated with fatigue in the Manitoba cohort of 280 patients [60].

Vitamin $\mathrm{B}_{12}$ and folate deficiency can also be linked to weakness and fatigue [59]. Folate deficiency and resultant macrocytic anemia can occur in the context of methotrexate (MTX) use or malabsorption [61]. $B_{12}$ deficiency and resultant macrocytic anemia can occur in patients with ileitis, ileal resection [62], or small intestinal bacterial overgrowth (SIBO) [63]. Anemia of chronic inflammation can occur in those with ongoing inflammation and impaired iron absorption and metabolism. Hemolysis can 
occur as a rare complication of IBD, as well as in association with IBD therapies, such as sulfasalazine and 5-aminosalicylates [64, 65]. Additionally, anemia as a component of bone marrow suppression is associated with azathioprine (AZA) and 6-mercaptopurine (6-MP) use, especially in those with thiopurine $S$-methyltransferase (TPMT) deficiency or intermediate level [66].

\section{Management of Anemia}

Routine complete blood cell count (CBC), ferritin, and CRP measurement are recommended every 3 months in patients with active disease and every 6-12 months for those in remission. Folate and vitamin $\mathrm{B}_{12}$ measurements are recommended annually or in the context of macrocytosis, according to the European Crohn's and Colitis Organization [67]. TPMT activity assessment prior to and routine cell count measurement during immunomodulator therapy are also recommended [68]. Basic anemia workup includes red blood cell indices, reticulocyte count, serum ferritin, transferrin saturation, and CRP measurement [67]. Further workup is generally performed in consultation with a hematologist if there is any confusion regarding etiology of the anemia.

Early and aggressive treatment of iron deficiency with parenteral or oral iron is recommended to improve IBD outcomes. The former is recommended in those with active IBD to maximize systemic bioavailability and avoid the risk of gastrointestinal toxicity with oral iron [69]. In a study of 543 patients, it was discovered that of the different parenteral iron preparations available, ferric carboxymaltose is most effective and safe with a response rate of $79 \%$, and with an adverse event rate of $12.0 \%$, and one serious adverse event (pulmonary embolism) [70]. Oral iron is preferred in motivated patients with inactive disease. The treat-to-target approach can be useful for the long-term management of iron deficiency, meaning that iron treatment should be continued with the goal of normalization of predetermined markers such as ferritin and iron saturation [71].
Vitamin $\mathrm{B}_{12}$ and folate should be supplemented if stores are discovered to be low. Folate supplementation of $1 \mathrm{mg} /$ day is the recommended dose. Folate is also recommended in patients taking methotrexate or sulfasalazine and a common component in prenatal vitamins, although the dose is less at $400 \mu \mathrm{g} /$ day [72, 73]. The recommended dose of $\mathrm{B}_{12}$ if deficiency is present is more than $1000 \mu \mathrm{g}$ daily orally [72]. However, the optimal method for vitamin $B_{12}$ supplementation is parenteral injections in those who have had more than $60 \mathrm{~cm}$ of ileum resected or have CD-related ileal inflammation resulting in disruption of ileal $\mathrm{B}_{12}$ absorption; $B_{12} 1000 \mu \mathrm{g}$ IM monthly is recommended for prophylaxis [74].

\section{Other Micronutrient Deficiencies}

Macro- and micronutrient deficiency can occur in patients with IBD as a result of several factors including malabsorption, diarrhea, self-imposed dietary restrictions, or a catabolic state and can lead to fatigue [75]. Restrictive diets carry the risk of nutritional deficiencies [76], e.g., gluten-free foods can be deficient in calcium, iron, niacin, and thiamine unless fortified [77]. Patients with IBD have inadequate intake of calcium, folate, and iron-containing foods [78]. Deficiencies of vitamin $B_{6}$, vitamin $B_{12}$, folate, ferritin, and zinc have all been linked to increased disease activity, while vitamin $\mathrm{D}$ deficiencies have been found in both diseaseactive patients and those in clinical remission [32, 78]. However, vitamin D deficiency has been shown to have no significant association with IBD in fatigue patients [79]. Testing for and replacing the deficient nutrient and ensuring a nutritionally replete diet, generally in collaboration with an experienced dietician, could improve symptoms, although data are limited [32].

\section{Concomitant Medications}

Less commonly, fatigue can be a direct medication-related adverse effect, e.g., due to AZA, 6-MP, or MTX rather than as a secondary mechanism of bone marrow suppression [32]. 
In a case series of five patients with IBD, discontinuation of 6-MP was associated with improvement in fatigue [80]. In addition, vedolizumab and infliximab both include fatigue as a potential side effect, occurring in $6 \%$ and $9 \%$ of patients, respectively. While steroids rapidly control inflammation and are associated with increase in energy and even insomnia, long-term use can cause myopathy and fatigue. Contrarily, adrenal insufficiency, manifested by severe fatigue, can occur with rapid steroid taper [81] and would warrant confirmation with early morning cortisol and ACTH measurement. Minderhoud et al. found no relationship of fatigue to clinically detectable adrenal insufficiency among a group of 80 well-described patients with IBD [82]. It will require higher power studies to elucidate if there is a correlation between fatigue and adrenal insufficiency in this population, suggesting that this avenue of investigation should be limited to those with high dose and prolonged steroid exposure.

Other medications, such as antidepressants and narcotics, more commonly prescribed to patients with IBD than the general population, can be associated with lethargy and somnolence [83]. In fact, narcotic use was associated with a significantly higher burden of fatigue in patients with IBD [84]. Cannabis use, especially by young patients with IBD, is associated with depressive symptoms [85] as well as a motivational syndrome, which may be interpreted as fatigue.

\section{Medication Reconciliation}

It is important to routinely review medication lists and consider withdrawing medications that could be associated with fatigue in the absence of other more likely explanation or after correction of identifiable risk factors. Fatigue in the presence of deep remission should warrant and a re-evaluation of potential culprit medications, including those used to treat IBD.

\section{Altered Gut Microbiome and Its Impact on the Gut-Brain Axis}

IBD is associated with dysbiosis and a decrease in the gut microbiome diversity, compared with healthy controls. In patients with IBD, there is a functional decreased composition of bacteroides and Faecalibacterium prausnitzii and an increased abundance of enteroaggregative Escherichia coli (EAEC) among many other changes to $\alpha / \beta$ diversity. Increased intestinal permeability from inflammation allows contents such as bacteria and bacterial metabolites to cross through the epithelial barriers into the systemic circulation [86]. These can act to incite the host immune system, resulting in systemic inflammation. Inflammatory cytokines increase permeability of the blood-brain axis, which may play a role in increased perception of fatigue symptoms. Evidence to support this hypothesis comes from studies performed on patients with chronic fatigue syndrome (CFS). Those with CFS have decreased stool bacterial diversity, similarly to those with IBD [87]. More recently, Borren et al., correlated a reduced abundance of Faecalibacterium spp. to patients with IBD with high fatigue and postulated that this affects the bidirectional flow of signals between the gut and the central nervous system, resulting in fatigue [87]. Interestingly, a recent systematic review showed that there were consistent changes in the microbiome of patients who responded to biologic agents, including infliximab, adalimumab, vedolizumab, and ustekinumab. There was a decrease in abundance of Escherichia and Enterococcus spp. and an increase in genera of short chain fatty acid producing species [88].

Our current strategies of microbial manipulation include antimicrobials, fecal bacteriotherapy, and probiotics. Antimicrobials have questions around their safety, specificity, and durability [89]. A systematic review of randomized control studies of probiotics found only support for a single formulation (VSL\#3) in a narrow indication of preventing UC relapse. However, this formulation as originally studied no longer exists under that trade name, but has been rebranded as Visibiome [90]. At this point, there are microbial changes associated with disease activity and fatigue, but currently no narrowly targeted strategy exists to manipulate the microbiome to manage fatigue. 


\section{Sleep Disturbance and Fatigue}

Sleep disturbances have been implicated as the cause of worsening symptoms including pain and fatigue in chronic inflammatory diseases. Poor sleep has become a keen area of research interest because it is thought to be an environmental factor that is closely linked to worsening IBD symptoms, specifically fatigue [91, 92]. Significant fatigue has been shown to be strongly correlated with poor sleep quality and daytime sleepiness [93]. Population-based sleep quality studies estimate that $32 \%$ of adults report poor sleep. Sleep deficiency is an even more common issue among patients with IBD with numerous authors including Graff et al. suggesting rates of problematic sleep in individuals with both active and inactive IBD to be greater than $50 \%[5,32,84,93-96]$.

\section{Patients with IBD Report Inadequate Sleep}

Survey studies confirm the presence of sleep concerns in patients with IBD. A majority of these studies utilized validated questionnaires to assess subjective sleep quality including the Pittsburgh Sleep Quality Index (PQSI), the Patient-Reported Outcomes Measurement Information System (PROMIS), the Modified Fatigue Impact Scale (MFIS), or the Epworth Sleepiness Scale (ESS). Data from these studies was consistent and patients with IBD, regardless of whether disease was quiescent or active, reported poorer sleep than healthy controls [5, 91, 97-104].

Subjective sleep assessments suggest that there is a strong association between IBD and sleep. Patients with IBD report worse sleep than healthy controls, and subjects with active IBD report poorer sleep than those in remission. Furthermore patients with IBD have inferior quality of life scores. In a case-control study, Ranjbaran et al. found that subjects with IBD identified prolonged sleep latency, increased fragmentation, use of sleeping aids, and decreased energy as factors associated with poorer overall sleep [91]. Another prospective cohort study corroborated the higher utilization of sleep medications in patients with IBD [100].
Factors limiting restorative sleep identified by study subjects in these surveys include pain from ongoing active disease and nocturnal symptoms. Other factors associated with poor sleep among patients with IBD include the use of steroids, narcotics, anti-TNF therapy, smoking, female sex, and depression [102, 105, 106]. Patients with IBD are vulnerable to the increasing obesity epidemic and are also at risk for obstructive sleep apnea (OSA) [107]. Interestingly a polysomnography study by Keefer et al. found that $13 \%$ of patients with IBD had OSA [108]. OSA prevalence is estimated to be around $20 \%$ in the overall population [109].

\section{Polysomnography Studies}

There is currently limited sleep data in patients with IBD through objective parameters. In the literature there are two studies using polysomnography and two studies utilizing wrist actigraphy. Actigraphy involves collecting data from a sensor worn on the non-dominant wrist during sleep. Computer-based algorithms help analyze sleep characteristics [110]. Although polysomnography remains the gold standard for sleep studies, wrist actigraphy has some advantages because it can be done in the patient's home environment, it is cost-effective, noninvasive, and less burdensome thus data can be collected over a longer period of time [110].

Keefer and colleagues were the first to perform a small prospective study using both subjective (PSQI) and objective (PSG) measures of sleep disturbances in healthy adult controls, patients with IBS, and patients with IBD [108]. In comparing the PSQI to PSG, self-reported hours of sleep were significantly correlated with PSG total sleep time. Subjects with IBD had poorer sleep quality by PQSI survey as well as polysomnography, when compared to healthy controls. However interestingly patients with IBD did not seem to score differently from patients with IBS on objective or subjective sleep parameters. Interestingly, these patients all had quiescent disease, suggesting that some other factor may be responsible for the experience of poorer sleep. 
Bar-Gil Shitrit et al. also found similar differences between patients with IBD with inactive disease and healthy controls in a polysomnography study [111]. They performed overnight polysomnography on 36 patients with inactive IBD and 27 healthy controls. The results showed a lower percentage of rapid eye movement (REM) sleep in subjects with IBD compared to healthy controls and more oxygen desaturation events not related to OSA.

Recently there was a small study that used the Fitbit Charge HR, a commercially available sleep monitor [106]. Data from wrist actigraphy studies in patients with IBD and polysomnography studies among patients with IBD were found to have longer sleep latency and lower sleep efficiency [97]. Additionally patients with IBD had greater numbers of nighttime awakenings [95]. In a study using the Fitbit charge HR, Sofia et al. found that sleep fragmentation was associated with increased chances of having clinically active disease [104].

\section{Science Behind IBD and Sleep Disturbance}

Sleep and the intricate relationship between sleep and IBD are a keen area of research interest because they are now thought to be an important environmental factor that may contribute to disease flares. There is good evidence about the link between sleep deprivation and the activation of the immune system, and the ability to mount an immune response [112]. In a meta-analysis of experimental sleep deprivation studies, sleep disturbances were associated with increases in CRP and IL-6 [113]. The largest studies that show a relationship between altered sleep patterns and inflammatory disorders are in shift workers. In one study, male electricians (OR 1.7) and male food and beverage industry workers (OR 1.6) had a statistically significant increased propensity for developing UC and $\mathrm{CD}$, which was thought to be related to irregular hours and interrupted sleep patterns [114]. Patients with IBD with poor sleep have increased rates of disease relapse, and lower sleep quality scores are predictive of subclinical histological inflammation and disease relapse at 6 months [101]. In another study, patients with
CD in remission had a twofold increased risk of disease recurrence at 6 months; however, this was not seen in patients with UC [102]. Ananthakrishnan et al. also found a higher incidence of UC in individuals with less than $6 \mathrm{~h}$ of sleep or more than $9 \mathrm{~h}$ of sleep [105].

There is basic science data that supports the observed relationship between sleep deprivation and increased inflammatory states. In experimental models of rodents with colitis and sleep deprivation, sleep deprivation worsened the degree of dextran sulfate (DSS)-induced colitis in animals [92]. Furthermore sleep elevations in pro-inflammatory markers (IL-6, $\mathrm{TNF} \alpha$, and CRP) in response to sleep deprivation have been seen in animal and human models [113, 115-118]. Interestingly administering IL-6 and TNF $\alpha$ to animals resulted in suppression of REM [119]. In humans, administration of endotoxins increased TNF $\alpha$, IL- 6 levels, and non-REM sleep and wakefulness [120].

\section{Treatment of Sleep Disturbances}

Poor sleep quality and resulting fatigue in the IBD population have implications for practitioners. Sleep deprivation is a modifiable risk factor and thus we need to incorporate sleep assessments more routinely for the care of our patients with IBD. Here we describe a datasupported strategy to address this issue in our patients.

Through induction of remission, gastroenterologists can significantly improve quality of sleep. Considering the effect of inflammation on sleep, it is intuitive that by decreasing disease activity, significant improvement in sleep can be achieved. Patients treated with vedolizumab and anti-TNF medications showed significant improvement in sleep survey scores with reduced nocturnal diarrhea and less abdominal pain [121]. It is also important for clinicians to identify iatrogenic risk factors for sleep impairment and modify treatment regimens. Effective interventions include cessation of steroid and narcotic use. Additionally given the association between sleep quality and psychiatric comorbidities, there is a need to screen for these conditions and refer for treatment [91]. 
When sleep quality is of concern, cognitive behavioral therapy (CBT) for sleep has been shown to be effective as a first-line intervention, and may have an important role in the care of patients with IBD [98]. Education about appropriate sleep hygiene is also important [122].

Recently cannabis has generated a lot of interest as an option for IBD symptom control. Furthermore many patients with IBD use cannabis as a complementary therapy for symptom control [52]. Patients with IBD report improved sleep with cannabis use, although this conclusion is based on a few small studies. In a study of young adults with IBD, disease activity scores for cannabis users were similar to non-users; however, there was a perceived positive impact on sleep quality reported by patients with IBD [123]. In another placebo-controlled study, IBD cannabis users reported significant improvement in sleep [56].

Melatonin, a natural hormone released by the pineal gland in response to the dark, shows some promise. Animal models show some decrease in inflammatory markers [124]. Rats who had induced colitis subsequently treated with melatonin showed improvement in the colitis [125, 126]. However, given limited human trial data, we do not routinely recommend this for our patients.

\section{CONCLUSION}

In summary, fatigue is a common and underrecognized symptom in patients with IBD that negatively impacts quality of life and can be a clinically challenging complaint to fully address. We have summarized the data to show a clear correlation between fatigue and disease activity, and that the first step in management of this complaint is to use medical therapy to achieve deep remission. In addition, it is clear that even in the population with well-controlled disease activity, fatigue remains a frequent complaint.

We have provided an algorithmic approach based on clinical experience (Fig. 2), from a single tertiary referral center for the systematic

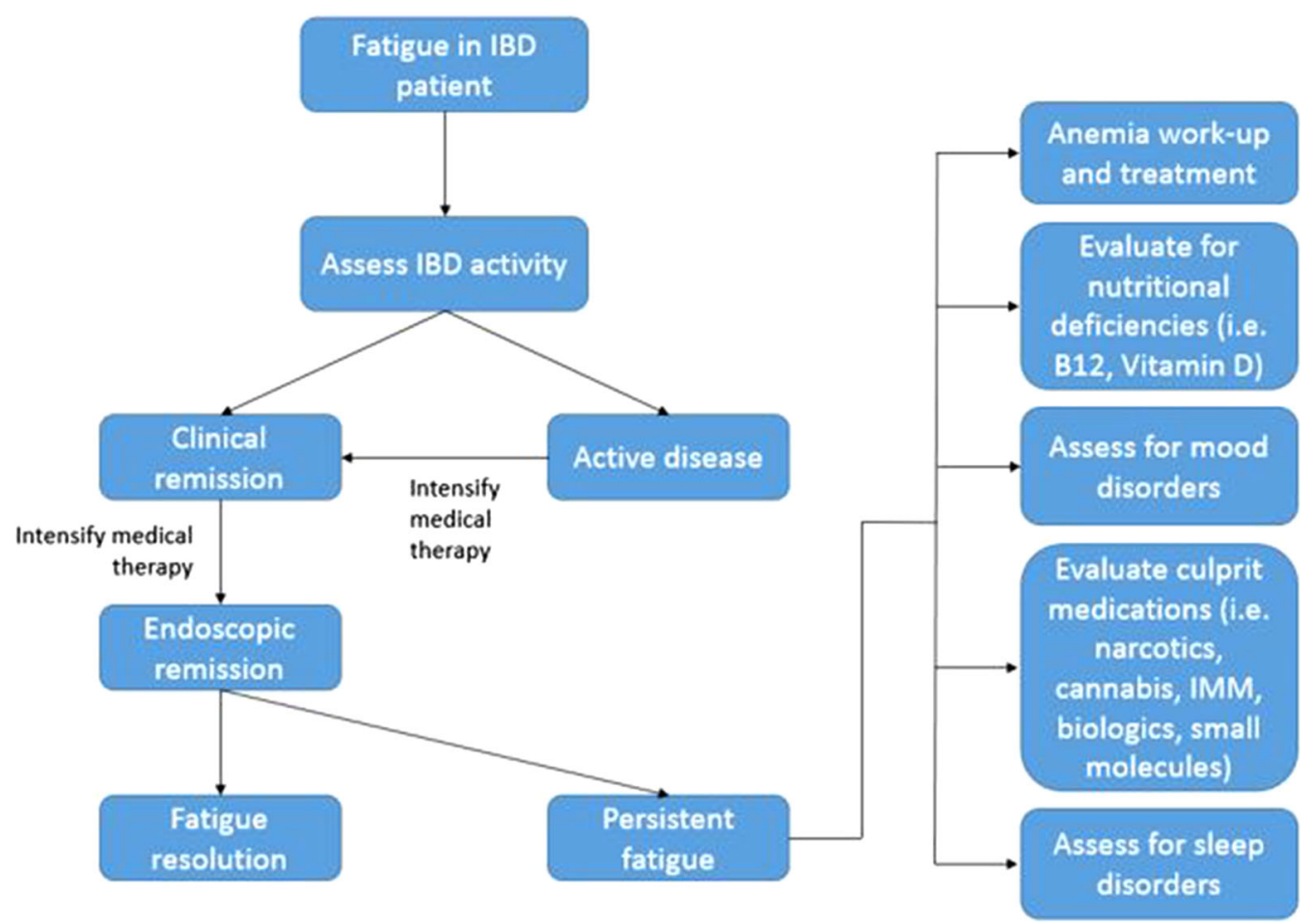

Fig. 2 Algorithm for the systematic workup of fatigue and treatment based on the etiology. IBD inflammatory bowel disease, $I M M$ immunomodulators 
workup of fatigue and treatment in patients with IBD. There exist many different assessment tools to measure fatigue, but most of the scales were developed in patients without IBD. The definition of fatigue varies across some of these scales, some referring to it as "low vitality", "low energy", and thus it is unclear if these studies are all measuring the same endpoint. In the absence an explanation despite an exhaustive evaluation among those in deep remission, we believe fatigue can be considered an extra-intestinal manifestation of IBD.

Currently, the reporting methodology of patient-reported outcomes (PROs) may obscure persistence of fatigue despite overall improvement in scores with specific treatments. A cohort of patients with IBD in deep remission and with complaints of fatigue will be needed to study the impact of the listed interventions to be able to provide a rigorous strategy for the management of fatigue in patients with IBD.

\section{ACKNOWLEDGEMENTS}

Funding. No funding or sponsorship was received for this study or publication of this article.

Authorship. All named authors meet the International Committee of Medical Journal Editors (ICMJE) criteria for authorship for this article, take responsibility for the integrity of the work as a whole, and have given their approval for this version to be published.

Authorship Contributions. Angelica Nocerino and Andrew Nguyen contributed equally to this work and should be acknowledged as cofirst authors.

Disclosures. Angelica Nocerino, Andrew Nguyen, Manasi Agrawal, Anjali Mone, and Komal Lakhani declare that they have no conflict of interest. Arun Swaminath serves as the principal investigator of studies funded by Abbvie, Gilead, Takeda, Trigenix, and Celgene. In addition, he has received educational grant funding from Takeda, Pfizer, Janssen, and Abbvie.
Compliance with Ethics Guidelines. This article is based on previously conducted studies and does not contain any studies with human participants or animals performed by any of the authors.

Data Availability. Data sharing is not applicable to this article as no datasets were generated or analyzed during the current study.

Open Access. This article is distributed under the terms of the Creative Commons Attribution-NonCommercial 4.0 International License (http://creativecommons.org/licenses/ by-nc/4.0/), which permits any noncommercial use, distribution, and reproduction in any medium, provided you give appropriate credit to the original author(s) and the source, provide a link to the Creative Commons license, and indicate if changes were made.

\section{REFERENCES}

1. Barsevick AM, Cleeland CS, Manning DC, et al. ASCPRO recommendations for the assessment of fatigue as an outcome in clinical trials. J Pain Sympt Manag. 2010;39(6):1086-99.

2. Czuber-Dochan W, Norton C, Bassett P, et al. Development and psychometric testing of inflammatory bowel disease fatigue (IBD-F) patient selfassessment scale. J Crohns Colitis. 2014;8(11): 1398-406.

3. Jelsness-Jørgensen LP, Bernklev T, Henriksen M, Torp R, Moum BA. Chronic fatigue is more prevalent in patients with inflammatory bowel disease than in healthy controls. Inflamm Bowel Dis. 2011;17(7):1564-72.

4. Grimstad T, Norheim KB, Isaksen K, et al. Fatigue in newly diagnosed inflammatory bowel disease. J Crohns Colitis. 2015;9(9):725-30.

5. Graff LA, Clara I, Walker JR, et al. Changes in fatigue over 2 years are associated with activity of inflammatory bowel disease and psychological factors. Clin Gastroenterol Hepatol. 2013;11(9):1140-6.

6. Huppertz-Hauss G, Hoivik ML, Jelsness-Jorgensen LP, et al. Fatigue in a population-based cohort of patients with inflammatory bowel disease 20 years after diagnosis: the IBSEN study. Scand J Gastroenterol. 2017;52(3):351-8. 
7. Lakhani KAM, Bhardwaj R, Swaminath A. Fatigue is inversely associated with endoscopic but not histologic remission in IBD patients. ACG Annual Scientific Meeting and Postgraduate Course. PO511. 2019 Oct 27.

8. Farrell D, McCarthy G, Savage E. Self-reported symptom burden in individuals with inflammatory bowel disease. J Crohns Colitis. 2016;10(3):315-22.

9. Jonefjall B, Simren M, Lasson A, Ohman L, Strid H. Psychological distress, iron deficiency, active disease and female gender are independent risk factors for fatigue in patients with ulcerative colitis. United Eur Gastroenterol J. 2018;6(1):148-58.

10. Bager P, Vestergaard C, Juul T, Dahlerup JF. Population-based normative data for the inflammatory bowel disease fatigue scale-IBD-F. Scand J Gastroenterol. 2018;53(10-11):1274-9.

11. Jelsness-Jørgensen LP, Bernklev T, Henriksen M, Torp R, Moum BA. Chronic fatigue is associated with impaired health-related quality of life in inflammatory bowel disease. Aliment Pharmacol Ther. 2011;33(1):106-14.

12. Romberg-Camps MJ, Bol Y, Dagnelie PC, et al. Fatigue and health-related quality of life in inflammatory bowel disease: results from a population-based study in the Netherlands: the IBD-South Limburg cohort. Inflamm Bowel Dis. 2010;16(12):2137-47.

13. Cohen BL, Zoëga H, Shah SA, et al. Fatigue is highly associated with poor health-related quality of life, disability and depression in newly-diagnosed patients with inflammatory bowel disease, independent of disease activity. Aliment Pharmacol Ther. 2014;39(8):811-22.

14. Zand A, van Deen WK, Inserra EK, et al. Presenteeism in inflammatory bowel diseases: a hidden problem with significant economic impact. Inflamm Bowel Dis. 2015;21(7):1623-30.

15. Enns MW, Bernstein CN, Kroeker $\mathrm{K}$, et al. The association of fatigue, pain, depression and anxiety with work and activity impairment in immune mediated inflammatory diseases. PLoS One. 2018;13(6):e0198975.

16. Smets EM, Garssen B, Bonke B, De Haes JC. The multidimensional fatigue inventory (MFI) psychometric qualities of an instrument to assess fatigue. J Psychosom Res. 1995;39(3):315-25.

17. Belza BL, Henke CJ, Yelin EH, Epstein WV, Gilliss CL. Correlates of fatigue in older adults with rheumatoid arthritis. Nurs Res. 1993;42(2):93-9.

18. Tinsley A, Macklin EA, Korzenik JR, Sands BE. Validation of the functional assessment of chronic illness therapy-fatigue (FACIT-F) in patients with inflammatory bowel disease. Aliment Pharmacol Ther. 2011;34(11-12):1328-36.

19. Chalder T, Berelowitz G, Pawlikowska T, et al. Development of a fatigue scale. J Psychosom Res. 1993;37(2):147-53.

20. Norton C, Czuber-Dochan W, Bassett P, et al. Assessing fatigue in inflammatory bowel disease: comparison of three fatigue scales. Aliment Pharmacol Ther. 2015;42(2):203-11.

21. van Langenberg DR, Gibson PR. Systematic review: fatigue in inflammatory bowel disease. Aliment Pharmacol Ther. 2010;32(2):131-43.

22. Irvine EJ, Feagan B, Rochon J, et al. Quality of life: a valid and reliable measure of therapeutic efficacy in the treatment of inflammatory bowel disease. Canadian Crohn's Relapse Prevention Trial Study Group. Gastroenterology. 1994;106(2):287-96.

23. Ware J, Kosinski M, Bjorner J, Turner-Bowker D, Gandek B, Maruish M. Development. User's Manual for the SF-36v2 ${ }^{\circledR}$ Health Survey. Lincoln (RI): QualityMetric Incorporated; 2007.

24. US Department of Health and Human Services Food and Drug Administration Center for Drug Evaluation and Research (CDER). Ulcerative colitis: clinical trial endpoints guidance for industry. $2016 \mathrm{Aug}$. https://www.fda.gov/regulatory-information/searchfda-guidance-documents/ulcerative-colitis-clinicaltrial-endpoints-guidance-industry. Accessed 12 Aug 2019.

25. Konig HH, Ulshofer A, Gregor M, et al. Validation of the EuroQol questionnaire in patients with inflammatory bowel disease. Eur J Gastroenterol Hepatol. 2002;14(11):1205-15.

26. Papanicolaou DA, Amsterdam JD, Levine S, et al. Neuroendocrine aspects of chronic fatigue syndrome. NeuroImmunoModulation. 2004;11(2):65-74.

27. Bower JE, Ganz PA, Aziz N, Fahey JL. Fatigue and proinflammatory cytokine activity in breast cancer survivors. Psychosom Med. 2002;64(4):604-11.

28. Patarca R. Cytokines and chronic fatigue syndrome. Ann N Y Acad Sci. 2001;933:185-200.

29. Vogelaar L, de Haar C, Aerts BR, et al. Fatigue in patients with inflammatory bowel disease is associated with distinct differences in immune parameters. Clin Exp Gastroenterol. 2017;10:83-90.

30. Carabotti M, Scirocco A, Maselli MA, Severi C. The gut-brain axis: interactions between enteric microbiota, central and enteric nervous systems. Ann Gastroenterol. 2015;28(2):203-9. 
31. Lucia Casadonte CJ, Brown J, Strople J, Neighbors K, Fei L, Alonso EM. Low insulin-like growth factor-1 influences fatigue and quality of life in children with inflammatory bowel disease. J Pediatr Gastroenterol Nutr. 2018;67(5):616-21.

32. Kreijne JE, Lie MR, Vogelaar L, van der Woude CJ. Practical guideline for fatigue management in inflammatory bowel disease. J Crohns Colitis. 2016;10(1):105-11.

33. Vogelaar L, van't Spijker A, van Tilburg AJ, Kuipers EJ, Timman R, van der Woude CJ. Determinants of fatigue in Crohn's disease patients. Eur J Gastroenterol Hepatol. 2013;25(2):246-51.

34. Artom M, Czuber-Dochan W, Sturt J, Norton C. Targets for health interventions for inflammatory bowel disease-fatigue. J Crohns Colitis. 2016;10(7): 860-9.

35. Gong J, Zuo L, Guo Z, et al. Impact of disease activity on resting energy expenditure and body composition in adult Crohn's disease: a prospective longitudinal assessment. JPEN J Parenter Enteral Nutr. 2015;39(6):713-8.

36. Elsherif Y, Alexakis C, Mendall M. Determinants of weight loss prior to diagnosis in inflammatory bowel disease: a retrospective observational study. Gastroenterol Res Pract. 2014;2014:762191.

37. Louati K, Berenbaum F. Fatigue in chronic inflammation-a link to pain pathways. Arthrit Res Ther. $2015 ; 17: 254$.

38. Dantzer R, O'Connor JC, Freund GG, Johnson RW, Kelley KW. From inflammation to sickness and depression: when the immune system subjugates the brain. Nat Rev Neurosci. 2008;9(1):46-56.

39. Villoria A, Garcia V, Dosal A, et al. Fatigue in outpatients with inflammatory bowel disease: prevalence and predictive factors. PLoS One. 2017;12(7): e0181435.

40. Chavarria C, Casanova MJ, Chaparro M, et al. Prevalence and factors associated with fatigue in patients with inflammatory bowel disease: a multicenter study. J Crohns Colitis. 2019;13(8): 996-1002.

41. Feagan BG, Yan S, Bala M, Bao W, Lichtenstein GR. The effects of infliximab maintenance therapy on health-related quality of life. Am J Gastroenterol. 2003;98(10):2232-8.

42. Loftus EV, Feagan BG, Colombel JF, et al. Effects of adalimumab maintenance therapy on health-related quality of life of patients with Crohn's disease: patient-reported outcomes of the CHARM trial. Am J Gastroenterol. 2008;103(12):3132-41.
43. Sandborn WJ, Feagan BG, Stoinov S, et al. Certolizumab pegol for the treatment of Crohn's disease. N Engl J Med. 2007;357(3):228-38.

44. Sands BE, Han C, Gasink C, et al. The effects of ustekinumab on health-related quality of life in patients with moderate to severe Crohn's disease. J Crohns Colitis. 2018;12(8):883-95.

45. Feagan BG, Reinisch W, Rutgeerts $P$, et al. The effects of infliximab therapy on health-related quality of life in ulcerative colitis patients. Am J Gastroenterol. 2007;102(4):794-802.

46. Sandborn WJ, van Assche G, Reinisch W, et al. Adalimumab induces and maintains clinical remission in patients with moderate-to-severe ulcerative colitis. Gastroenterology. 2012;142(2):257-65.e3.

47. Feagan BG, Patel H, Colombel JF, et al. Effects of vedolizumab on health-related quality of life in patients with ulcerative colitis: results from the randomised GEMINI 1 trial. Aliment Pharmacol Ther. 2017;45(2):264-75.

48. Panes J, Vermeire S, Lindsay JO, et al. Tofacitinib in patients with ulcerative colitis: health-related quality of life in phase 3 randomised controlled induction and maintenance studies. J Crohns Colitis. 2018;12(2):145-56.

49. Probert CS, Sebastian S, Gaya DR, et al. Golimumab induction and maintenance for moderate to severe ulcerative colitis: results from GO-COLITIS (Golimumab: a Phase 4, UK, open label, single arm study on its utilization and impact in ulcerative Colitis). BMJ Open Gastroenterol. 2018;5(1):e000212.

50. Grimstad T, Norheim KB, Kvaløy JT, et al. Conventional treatment regimens for ulcerative colitis alleviate fatigue-an observational cohort study. Scand J Gastroenterol. 2016;51(10):1213-9.

51. Casellas F, de Barreiro Acosta M, Iglesias M, et al. Mucosal healing restores normal health and quality of life in patients with inflammatory bowel disease. Eur J Gastroenterol Hepatol. 2012;24(7):762-9.

52. Swaminath A, Berlin EP, Cheifetz A, et al. The role of cannabis in the management of inflammatory bowel disease: a review of clinical, scientific, and regulatory information. Inflamm Bowel Dis. 2019;25(3):427-35.

53. Howlett AC, Barth F, Bonner TI, et al. International union of pharmacology. XXVII. Classification of cannabinoid receptors. Pharmacol Rev. 2002;54(2): 161-202.

54. Izzo AA, Sharkey KA. Cannabinoids and the gut: new developments and emerging concepts. Pharmacol Ther. 2010;126(1):21-38. 
55. Lal S, Prasad N, Ryan M, et al. Cannabis use amongst patients with inflammatory bowel disease. Eur J Gastroenterol Hepatol. 2011;23(10):891-6.

56. Naftali T, Bar-Lev Schleider L, Dotan I, Lansky EP, Sklerovsky Benjaminov F, Konikoff FM. Cannabis induces a clinical response in patients with Crohn's disease: a prospective placebo-controlled study. Clin Gastroenterol Hepatol. 2013;11(10):1276-80.

57. Irving PM, Iqbal T, Nwokolo C, et al. A randomized, double-blind, placebo-controlled, parallel-group, pilot study of cannabidiol-rich botanical extract in the symptomatic treatment of ulcerative colitis. Inflamm Bowel Dis. 2018;24(4):714-24.

58. Bager P, Befrits R, Wikman O, et al. The prevalence of anemia and iron deficiency in IBD outpatients in Scandinavia. Scand J Gastroenterol. 2011;46(3): 304-9.

59. Gasche C, Lomer MC, Cavill I, Weiss G. Iron, anaemia, and inflammatory bowel diseases. Gut. 2004;53(8):1190-7.

60. Goldenberg BA, Graff LA, Clara I, et al. Is iron deficiency in the absence of anemia associated with fatigue in inflammatory bowel disease? Am J Gastroenterol. 2013;108(9):1392-7.

61. Madanchi M, Fagagnini S, Fournier N, et al. The relevance of vitamin and iron deficiency in patients with inflammatory bowel diseases in patients of the Swiss IBD cohort. Inflamm Bowel Dis. 2018;24(8): 1768-79.

62. Battat R, Kopylov U, Szilagyi A, et al. Vitamin B12 deficiency in inflammatory bowel disease: prevalence, risk factors, evaluation, and management. Inflamm Bowel Dis. 2014;20(6):1120-8.

63. Egan LJ, Sandborn WJ. Methotrexate for inflammatory bowel disease: pharmacology and preliminary results. Mayo Clin Proc. 1996;71(1):69-80.

64. Guagnozzi D, Lucendo AJ. Anemia in inflammatory bowel disease: a neglected issue with relevant effects. World J Gastroenterol. 2014;20(13): 3542-51.

65. Plikat K, Rogler G, Scholmerich J. Coombs-positive autoimmune hemolytic anemia in Crohn's disease. Eur J Gastroenterol Hepatol. 2005;17(6):661-6.

66. Schwab M, Schaffeler E, Marx C, et al. Azathioprine therapy and adverse drug reactions in patients with inflammatory bowel disease: impact of thiopurine S-methyltransferase polymorphism. Pharmacogenetics. 2002;12(6):429-36.

67. Dignass AU, Gasche C, Bettenworth D, et al. European consensus on the diagnosis and management of iron deficiency and anaemia in inflammatory bowel diseases. J Crohns Colitis. 2015;9(3):211-22.

68. Lichtenstein GR, Loftus EV, Isaacs KL, Regueiro MD, Gerson LB, Sands BE. ACG clinical guideline: management of Crohn's disease in adults. Am J Gastroenterol. 2018;113(4):481-517.

69. Hou JK, Gasche C, Drazin NZ, et al. Assessment of gaps in care and the development of a care pathway for anemia in patients with inflammatory bowel diseases. Inflamm Bowel Dis. 2017;23(1):35-43.

70. Aksan A, Isik H, Radeke HH, Dignass A, Stein J. Systematic review with network meta-analysis: comparative efficacy and tolerability of different intravenous iron formulations for the treatment of iron deficiency anaemia in patients with inflammatory bowel disease. Aliment Pharmacol Ther. 2017;45(10):1303-18.

71. Peyrin-Biroulet L, Lopez A, Cummings JRF, Dignass A, Detlie TE, Danese S. Review article: treating-totarget for inflammatory bowel disease-associated anaemia. Aliment Pharmacol Ther. 2018;48:610-7.

72. Eiden KA. Nutritional consideration in inflammatory bowel disease. Pract Gastroenterol. 2003;27: $33-54$

73. Bulletins-Obstetrics CoP. Practice Bulletin No. 187: Neural Tube Defects. Obstet Gynecol 2017;130(6): e279-90.

74. Hwang C, Ross V, Mahadevan U. Micronutrient deficiencies in inflammatory bowel disease: from A to zinc. Inflamm Bowel Dis. 2012;18(10):1961-81.

75. Lucendo AJ, De Rezende LC. Importance of nutrition in inflammatory bowel disease. World J Gastroenterol. 2009;15(17):2081-8.

76. Limketkai BN, Wolf A, Parian AM. Nutritional interventions in the patient with inflammatory bowel disease. Gastroenterol Clin N Am. 2018;47(1):155-77.

77. Allen B, Orfila C. The availability and nutritional adequacy of gluten-free bread and pasta. Nutrients. 2018;10(10):1370.

78. Vagianos K, Bector S, McConnell J, Bernstein CN. Nutrition assessment of patients with inflammatory bowel disease. JPEN J Parenter Enteral Nutr. 2007;31(4):311-9.

79. Frigstad SO, Høivik ML, Jahnsen J, et al. Fatigue is not associated with vitamin $\mathrm{D}$ deficiency in inflammatory bowel disease patients. World J Gastroenterol. 2018;24(29):3293-301.

80. Lee TW, Iser JH, Sparrow MP, Newnham ED, Headon BJ, Gibson PR. Thiopurines, a previously 
unrecognised cause for fatigue in patients with inflammatory bowel disease. J Crohns Colitis. 2009;3(3):196-9.

81. Ibrahim A, Dahlqvist P, Olsson T, et al. The clinical course after glucocorticoid treatment in patients with inflammatory bowel disease is linked to suppression of the hypothalamic-pituitary-adrenal axis: a retrospective observational study. Therap Adv Gastroenterol. 2017;10(11):829-36.

82. Minderhoud IM, Oldenburg B, van Dam PS, van Berge Henegouwen GP. High prevalence of fatigue in quiescent inflammatory bowel disease is not related to adrenocortical insufficiency. Am J Gastroenterol. 2003;98(5):1088-93.

83. Docherty MJ, Jones RCW, Wallace MS. Managing pain in inflammatory bowel disease. Gastroenterol Hepatol. 2011;7(9):592-601.

84. Hashash JG, Ramos-Rivers C, Youk A, et al. Quality of sleep and coexistent psychopathology have significant impact on fatigue burden in patients with inflammatory bowel disease. J Clin Gastroenterol. 2018;52(5):423-30.

85. Leadbeater BJ, Ames ME, Linden-Carmichael AN. Age-varying effects of cannabis use frequency and disorder on symptoms of psychosis, depression, and anxiety in adolescents and adults. Addiction. 2019;114(2):278-93.

86. Clapp M, Aurora N, Herrera L, Bhatia M, Wilen E, Wakefield S. Gut microbiota's effect on mental health: the gut-brain axis. Clin Pract. 2017;7(4):987.

87. Borren NZ, van der Woude CJ, Ananthakrishnan AN. Fatigue in IBD: epidemiology, pathophysiology and management. Nat Rev Gastroenterol Hepatol. 2019;16(4):247-59.

88. Estevinho MM, Rocha C, Correia L, et al. Features of fecal and colon microbiomes associate with responses to biologic therapies for inflammatory bowel diseases: a systematic review. Clin Gastroenterol Hepatol. 2019. https://doi.org/10.1016/j.cgh. 2019.08.063.

89. Longman RS, Swaminath A. Microbial manipulation as primary therapy for Crohn's disease. World J Gastroenterol. 2013;19(10):1513-6.

90. P\&T Community. ExeGi wins court ruling against VSL\# ${ }^{\circledR *}$, permanent injunction blocks false advertising to doctors, consumers. 2019 Jun. https:// www.ptcommunity.com/wire/exegi-wins-court-ruli ng-against-vsl3-permanent-injunction-blocks-falseadvertising-doctors. Accessed 12 Aug 2019.

91. Ranjbaran Z, Keefer L, Stepanski E, Farhadi A, Keshavarzian A. The relevance of sleep abnormalities to chronic inflammatory conditions. Inflamm Res. 2007;56(2):51-7.

92. Tang Y, Preuss F, Turek FW, Jakate S, Keshavarzian A. Sleep deprivation worsens inflammation and delays recovery in a mouse model of colitis. Sleep Med. 2009;10(6):597-603.

93. Graff LA, Vincent N, Walker JR, et al. A populationbased study of fatigue and sleep difficulties in inflammatory bowel disease. Inflamm Bowel Dis. 2011;17(9):1882-9.

94. Chrobak AA, Nowakowski J, Zwolinska-Wcislo M, et al. Associations between chronotype, sleep disturbances and seasonality with fatigue and inflammatory bowel disease symptoms. Chronobiol Int. 2018;35(8):1142-52.

95. van Langenberg DR, Papandony MC, Gibson PR. Sleep and physical activity measured by accelerometry in Crohn's disease. Aliment Pharmacol Ther. 2015;41(10):991-1004.

96. Swanson GR, Burgess HJ, Keshavarzian A. Sleep disturbances and inflammatory bowel disease: a potential trigger for disease flare? Exp Rev Clin Immunol. 2011;7(1):29-36.

97. Burgess HJ, Swanson GR, Keshavarzian A. Endogenous melatonin profiles in asymptomatic inflammatory bowel disease. Scand J Gastroenterol. 2010;45(6):759-61.

98. Graff LA, Walker JR, Russell AS, Bissonnette R, Bernstein CN. Fatigue and quality of sleep in patients with immune-mediated inflammatory disease. J Rheumatol Supp. 2011;88:36-42.

99. Zimmerman J. Extraintestinal symptoms in irritable bowel syndrome and inflammatory bowel diseases: nature, severity, and relationship to gastrointestinal symptoms. Dig Dis Sci. 2003;48(4): 743-9.

100. Gingold-Belfer R, Peled N, Levy S, et al. Impaired sleep quality in Crohn's disease depends on disease activity. Dig Dis Sci. 2014;59(1):146-51.

101. Ali T, Madhoun MF, Orr WC, Rubin DT. Assessment of the relationship between quality of sleep and disease activity in inflammatory bowel disease patients. Inflamm Bowel Dis. 2013;19(11):2440-3.

102. Ananthakrishnan AN, Long MD, Martin CF, Sandler RS, Kappelman MD. Sleep disturbance and risk of active disease in patients with Crohn's disease and ulcerative colitis. Clin Gastroenterol Hepatol. 2013;11(8):965-71.

103. Wilson RG, Stevens BW, Guo AY, et al. High C-reactive protein is associated with poor sleep quality 
independent of nocturnal symptoms in patients with inflammatory bowel disease. Dig Dis Sci. 2015;60(7):2136-43.

104. Sofia MA, Andersen M, Rubin DT. Sleep dysfunction and inflammatory bowel disease. Sleep effect on gastrointestinal health and disease: translational opportunities for promoting health and optimizing disease management. New York: Nova Science; 2018. p. 177-99.

105. Ananthakrishnan AN, Khalili H, Konijeti GG, et al. Sleep duration affects risk for ulcerative colitis: a prospective cohort study. Clin Gastroenterol Hepatol. $2014 ; 12(11): 1879-86$.

106. Qazi T, Farraye FA. Sleep and inflammatory bowel disease: an important bi-directional relationship. Inflamm Bowel Dis. 2019;25(5):843-52.

107. Singh S, Dulai PS, Zarrinpar A, Ramamoorthy S, Sandborn WJ. Obesity in IBD: epidemiology, pathogenesis, disease course and treatment outcomes. Nat Rev Gastroenterol Hepatol. 2017;14(2): 110-21.

108. Keefer L, Stepanski EJ, Ranjbaran Z, Benson LM, Keshavarzian A. An initial report of sleep disturbance in inactive inflammatory bowel disease. J Clin Sleep Med. 2006;2(4):409-16.

109. Young T, Peppard PE, Gottlieb DJ. Epidemiology of obstructive sleep apnea: a population health perspective. Am J Respir Crit Care Med. 2002;165(9): 1217-39.

110. Walia HK, Mehra R. Practical aspects of actigraphy and approaches in clinical and research domains. In: Kerry H, Levin PC, editors. Handbook of clinical neurology, vol. 160. New Work: Elsevier; 2019. p. 371-9.

111. Bar-Gil Shitrit A, Chen-Shuali C, et al. Sleep disturbances can be prospectively observed in patients with an inactive inflammatory bowel disease. Dig Dis Sci. 2018;63(11):2992-7.

112. Krueger JM. The role of cytokines in sleep regulation. Curr Pharm Des. 2008;14(32):3408-16.

113. Irwin MR, Wang M, Campomayor CO, Collado-Hidalgo A, Cole S. Sleep deprivation and activation of morning levels of cellular and genomic markers of inflammation. Arch Intern Med. 2006;166(16): 1756-62.

114. Sonnenberg A. Occupational distribution of inflammatory bowel disease among German employees. Gut. 1990;31(9):1037-40.
115. Born J, Lange T, Hansen K, Molle M, Fehm HL. Effects of sleep and circadian rhythm on human circulating immune cells. J Immunol. 1997;158(9): 4454-64.

116. Haack M, Sanchez E, Mullington JM. Elevated inflammatory markers in response to prolonged sleep restriction are associated with increased pain experience in healthy volunteers. Sleep. 2007;30(9): $1145-52$.

117. Uthgenannt D, Schoolmann D, Pietrowsky R, Fehm HL, Born J. Effects of sleep on the production of cytokines in humans. Psychosom Med. 1995;57(2): 97-104.

118. Vgontzas AN, Papanicolaou DA, Bixler EO, Kales A, Tyson K, Chrousos GP. Elevation of plasma cytokines in disorders of excessive daytime sleepiness: role of sleep disturbance and obesity. J Clin Endocrinol Metab. 1997;82(5):1313-6.

119. Shoham S, Davenne D, Cady AB, Dinarello CA, Krueger JM. Recombinant tumor necrosis factor and interleukin 1 enhance slow-wave sleep. Am J Physiol. 1987;253(1 Pt 2):R142-9.

120. Mullington J, Korth C, Hermann DM, et al. Dosedependent effects of endotoxin on human sleep. Am J Physiol Regul Integr Comp Physiol. 2000;278(4):R947-55.

121. Stevens BW, Borren NZ, Velonias G, et al. Vedolizumab therapy is associated with an improvement in sleep quality and mood in inflammatory bowel diseases. Dig Dis Sci. 2017;62(1):197-206.

122. Watson NF, Lawlor C, Raymann R. Consumer sleep technologies, clinical guidelines, and evidencebased medicine: this is not a zero-sum game. J Clin Sleep Med. 2019;15(5):797-8.

123. Hoffenberg EJ, McWilliams S, Mikulich-Gilbertson S, Murphy B, Hoffenberg A, Hopfer CJ. Cannabis oil use by adolescents and young adults with inflammatory bowel disease. J Pediatr Gastroenterol Nutr. 2019;68(3):348-52.

124. Park YS, Chung SH, Lee SK, et al. Melatonin improves experimental colitis with sleep deprivation. Int J Mol Med. 2015;35(4):979-86.

125. $\mathrm{Li} \mathrm{JH}, \mathrm{Yu} \mathrm{JP}$, et al. Melatonin reduces inflammatory injury through inhibiting NF-kappaB activation in rats with colitis. Mediat Inflamm. 2005;2005(4): 185-93.

126. Mei Q, Yu JP, Xu JM, Wei W, Xiang L, Yue L. Melatonin reduces colon immunological injury in rats by regulating activity of macrophages. Acta Pharmacol Sin. 2002;23(10):882-6. 